\title{
Suicide among Undergraduate Students in Southeast Nigeria: An Empirical Evaluation of Durkheim's Classifications of Suicide
}

\author{
Samuel O. Okafor \\ University of Nigeria, Nsukka, NIGERIA \\ Department of Sociology/Anthropology
}

Received: 14 August 2020 - Accepted: 27 October 2020 • Published Online: 29 November 2020

\begin{abstract}
The Durkheimian sociological doctrine of suicide is classified into regulation/integration, high and low social currents, with four resultant suicide types such as egoistic, altruistic, anomic and fatalistic suicide. Across Nigeria and social classes, suicide types and circumstances according to the above classifications have become worrisome, warranting empirical investigation into the social wellbeing and suicide potentials in the social realm of Nigerian socio-economic and political landscape. As such, this study investigated the suicide tendency among undergraduate students in some selected institutions of higher learning in south-eastern Nigeria. The study adopted a survey design using a sample size of 2,200 students (17+). The study adopted parametric statistics for the test of the relationship of variables. In the overall findings, altruistic suicide tendency is high (60\%), this is followed by anomic suicide tendency (47\%), egoistic suicide tendency (46\%) and fatalistic suicide tendency (41\%). From the regression model ( $\mathrm{p}<$ .05), altruistic suicide tendency was found to be predicted by family income and strong ties with family activities. Equally, anomic suicide tendency can be predicted by how many years the students have been in the school. Egoistic suicide tendency was found to be positively correlated with family income and source of sponsorship while fatalistic suicide tendency was found to be positively correlated with only family income.
\end{abstract}

Keywords: suicide tendency, anomic suicide, egoistic suicide, fatalistic suicide, altruistic suicide, Durkheimian suicide doctrine.

\section{Introduction}

Suicide as a social phenomenon is embedded in the prevailing socio-economic circumstances of the time and by implication, vulnerable to the negative or positive direction and influence of the indices of the socio-economic situation of the time (White \& Morris, 2019; O'Connor \& Nock, 2014). While suicide in its own right is human action, the action itself is an outcome of social circumstances. Across the ages and societies, the phenomenon of suicide has taken different shapes and meanings, making it more or less, object of scientific interest other than emotional circumstance demanding sympathy.

Suicide in antiquity has existed without a formal understanding of it as a social menace as such until the moment the French sociologist (Emile Durkheim) approached such in a scientific attempt (Haralambose \& Holborn, 2008), bringing it to the limelight of the scholarly community.

(C) Authors. Terms and conditions of Creative Commons Attribution 4.0 International (CC BY 4.0) apply. Correspondence: Samuel O. Okafor, University of Nigeria, Department of Sociology/Anthropology, Nsukka, NIGERIA. E-mail: samuelokey200@gmail.com. 
Among other things, suicide was perceived as cultural practices among some ethnic and tribal groups while in some situations, it never appeared as a social problem (Baechler, 1979). With the work of Durkheim, which set the platform for the understanding of suicide as a social problem as well as worthy of scientific exploration, many interests were developed in understanding, classifying, predicting and controlling suicide phenomenon (João et al., 2016; Baechler, 1979; Taylor, 1982). As such, many scholars mostly on the platform of social science have put the phenomenon into consideration as one of the social problems to date, which required serious attention (Holmes, Crane, Fennell \& Williams, 2007; White \& Morris, 2019; O’Connor \& Nock, 2014).

Following the unrestrained interest in the study of suicide, many understandings about the phenomenon have emerged increasing, the arguments about research methodology suitable for the study of suicide (Atkinson, 1978; Philipson, 1972; Taylor, 1982; Dorais, 2004; White \& Morris, 2019). These equally, have enabled a large scope of interests and pieces of literature in the study of suicide, while creating numerous approaches in the study and interpretations of suicide phenomenon (Lester, 2001; Henry \& Short, 1954; Chandler, 2019; Hjelmeland \& Knizek, 2010). While Durkheim started with the macro-social phenomenon such as the socioeconomic factors (religion, politics, family, and economy), and positivist methodology (Durkheim, 1897; Haralambose \& Holborn, 2008), other scholars such as Douglas (1967), Baechler (1979), Dorais (2004), Atkinson (1978), Philipson (1972), Taylor (1982), and host of others, have approached the phenomenon of suicide scientifically, using different methodologies and objects of interest other than that of Durkheim.

The peculiarity of Durkheim's approach is found in the fact that other arguments and approaches have one similarity or the other with Durkheim's approach making it, one of the enduring sociological and perhaps social scientific approaches to suicide to date (Hindess, 1973; Scourfield et al., 2012). As such, the relevance of Durkheim's sociological suicide doctrine cannot be overemphasized in the effort to understand the remote and immediate factors behind suicide tendencies, potentials, and ideation.

In recent times, the issue of suicide across the globe has become really a social problem demanding scholarly efforts from different disciplinary quarters in order to combat suicide as a social menace. According to World Health Organization (2019), about 800,000 people die by suicide annually. In the current historical epoch ( $21^{\text {st }}$ century), suicide and suicide tendencies have increased to alarming rate according to empirical documentations from different parts of the globe (Scourfield et al., 2012; João et al., 2016; Boycea et al., 2018; Mars et al., 2014; Holmes, Crane, Fennell \& Williams, 2007; White \& Morris, 2019; O'Connor \& Nock, 2014), with a large chunk of the reported suicide in the developed world (Mars et al, 2014; Holmes, Crane, Fennell \& Williams, 2007; White \& Morris, 2019; O’Connor \& Nock, 2014; Holt, et al., 2015). Equally, evidences abound that the large chunk of unreported suicide are located in the developing world such as Africa (Adewuya et al., 2016). Although there are scholars in the two polarized zones, the differences in suicide reporting and documentation still lie on the extent of psycho and sociohuman development in the understanding, management and reporting of death related phenomenon (Okafor, 2017). Consequently, most African nations such as Nigeria are still battling with unclassified reports on suicide phenomenon making it necessary for the use of macro socioeconomic elements in the screening of suicide occurrence, ideation, and tendencies.

The suicide rate in Nigeria (3.2\%) is among the disturbing digits, among African and other developing nations (Adewuya et al., 2016; Mars et al., 2014). It is such that deserves sociological investigations, for the understanding, analysis and possible control of the phenomenon. World over, the majority of the reported suicide and sometimes unreported suicides have been documented among the youth (Holmes, Crane, Fennell \& Williams, 2007; White \& Morris, 2019; O'Connor \& Nock, 2014; Skinner \& McFaull, 2012; Fact sheet, 2010). The same trend appears to be the case in sub-Saharan Africa, including Nigeria (Adewuya et al., 2016; Mars 
et al., 2014). More concerns are the fact that unreported suicide actions are more than the reported suicide actions (Mars et al., 2014), coupled with the fact that government and other concerned agencies lack scientific information on the barometers to follow to control remote and immediate suicide tendencies. In view of the need for understanding and controlling suicide phenomenon especially among the undergraduate youth in Nigeria, the present study is designed to investigate suicide potential and ideation among the undergraduate students from south-eastern Nigerian higher institutions of learning. Among other things, the study investigated:

(1) Micro cum macro socio-economic factors determining egoistic suicide tendency (potential) among the undergraduate students, in view of Durkheim's classification of suicides based on suicide;

(2) Micro cum macro socio-economic factors determining altruistic suicide tendency (potential) among the undergraduate students, in view of Durkheim's classification of suicides based on suicide;

(3) Micro cum macro socio-economic factors determining anomic suicide tendency (potential) among the undergraduate students, in view of Durkheim's classification of suicides based on suicide;

(4) Micro cum macro socio-economic factors determining fatalistic suicide tendency (potential) among the undergraduate students, in view of Durkheim's classification of suicides based on suicide;

(5) The most likely form of suicide tendency/potential (such as egoistic, altruistic, fatalistic and anomic suicide) among the undergraduate students in this area of the world.

\section{Review of relevant literatures}

Suicide, the unnatural death as a result of self-harm, is one of the enduring social problems of the current historical epoch. From the time of Durkheim (1897), who first classified the phenomenon for the more scientific approach, to the present, suicide has been a burden on many nations as well as the global body (World Health Organization) (Coop et al., 2014). Suicide has affected productivity and economic growth especially in the developed nations (Boyce, Wood \& Ferguson, 2016); it has caused both micro and macro socio-economic challenges bordering on all aspects of life (Hawton \& van Heeringen, 2009; Hawton, Saunders \& O’Connor, 2012).

Although documentation on suicide as one of the social problems of the century is irregular in some nations, the available documentation so far presents some level of concern both to the researchers' community and that of the policymakers world over (Nock, Borges \& Bromet, 2008; Nock, Borges \& Ono, 2012). This is a result of the fact that many suicide actions, attempts, and ideation are mostly hidden especially among the developing nations (Holmes, Crane, Fennell \& Williams, 2007; White \& Morris, 2019; O'Connor \& Nock, 2014).

Across the globe, there are a number of documentations indicating the trends of suicide and its overwhelming calling for more scientific investigations (Nock, Borges \& Bromet, 2008). A number of researches in Europe have indicated the epidemiological posture of suicide over some decades (Gunnell et al., 2012; Saurina et al, 2013; Chang, Stuckler, Yip \& Gunnell, 2013; Mills, 2018); in the United States of America, suicide has taken a dramatic turn in a number of decades defying, the power of social policies designed to mitigate such (Spates \& Slatton, 2017; Sean et al., 2009; Reeves et al., 2012; Furr, Westefeld, McConnell \& Jenkins, 2001; Borowsky, Resnick, Ireland \& Blum, 1999; Fitzpatrick, 2018). Among the population in Canada, suicide incidents among the youth has appeared as one of the enduring challenges to the public health institution. Although this appears with some level of disparities among the sub social groups, the occurrence is relatively high in aggregate when compared to other developed nations (Kirmayer, Brass, Holton, Paul, Simpson \& Tait, 2007; Pollock, Healy, Jong, Valcour \& Mullay, 2018). 
According to World Bank Group (2017) documentation and classification, most of the world's suicides were recorded in low-and-middle-income countries (79\%). However, the highest age-standardized suicide rate were observed in high-income countries (11.5 per 100,000), compared to Lower-middle-income (11.4 per 100,000). Also, lower rates of age-standardized suicide was recorded in low-income and upper-middle-income countries (10.8 per 100,000 and 9.0 per 100,000 respectively). On male/female suicide ration, females in lower-middle-income countries had the highest suicide rate (9.1 per 100,000) compared to females in other income level groupings while, males in high-income countries had the highest rate $(17.2$ per 100,000) as compared to males in other income level groupings (WHO, 2019; World Bank Group, 2017).

Among the regions of the globe, World Health Organization (2016) documentation put suicide rates in Africa (12.0 per 100,000), Europe (12.9 per 100,000), and South-East Asia (13.4 per 100,000) regions as higher than the global average (10.5 per 100,000). The lowest suicide rate in comparison was in the Eastern Mediterranean region (4.3 per 100,000). There is a much higher female age-standardized suicide rates in the South-East Asia Region (11.5 per 100,000) when compared to the global female average (7.5 per 100,000). For males, the regions of Africa (16.6 per 100,000), the Americas (14.5 per 100,000), South-East Asia (15.4 per 100,000), and especially Europe (21.2 per 100,000), all surpassed the global male average (13.7 per 100,000) (WHO, 2018; 2019).

Among the African nations, depending on the available documentation, suicide rates across the continents has continued to grow as a result degenerating socioeconomic situation in the continent. While the suicide rate in Ghana was reported to be 5.4 against every 100,000 population, the ratio of 10:1 was equally documented (i.e. 10 men against every 1 woman) (Adinkrah, 2011; WHO, 2016; 2019).

By 2008, Johnson et al. (2008) reported that the suicide rate in Liberia was $6 \%$ of which the male/female ratio was 0.7:1. However, the WHO report (2018) put the suicide rate for both sexes at 6.8\%. In Morocco, Agoub Moussaoui \& Kadri (2006) using the region of Casablanca, reported suicide-related deaths and suicide prevalence of $2.1 \%$ with male/female ratio of 0.5:1. Gureje et al. (2007), using the Nigerian six geopolitical zones, investigated the rate of suicide across the nation. According to their findings, the suicide prevalence was $0.7 \%$ with a male/female ratio of 1.0:1. The WHO report (2018a) put the overall suicide rate in Nigeria at 9.5\% (9.2 for females and 9.9 for males).

According to the study by Bekry (1999), which focused on Addis Ababa Ethiopia (19811996), revealed that the suicide rate among the population was as high as 49.8 per 100,000 with male/female ratio of 2.9:1. Taking a sample from Blantyre Malawi (2000-2003) by Dzamalala et al. (2006), suicide prevalence was recorded at 10.7 per 100,000 with the male/female ratio of o.8:1. From Namibia, Ikealumba and Couper (2006) from their study reported the prevalence of suicide to be 100.0 per 100,000 with a male/female ratio of 0.9:1.

As at the time, 2002-2004, the study by Joe et al. (2008), which focused on South Africa, showed the lifetime prevalence of suicide of $2.9 \%$ with the male/female ratio of $0.3: 1$. However, the report of the World Health Organization (2018b) put the suicide rate in South Africa as $11.6 \%$. According to a study in Kampala Uganda in January 2001-Oct 2002, which was reported by Kinyanda, Hjelmeland and Musisi (2004), the suicide prevalence in Uganda was shown to be 10.1 per 100,000 with male/female ratio of 1.7:1. Similarly, the study by Ndosi and Waziri (1997) in Dar es Salaam Tanzania between 1991- 1993 revealed a suicide prevalence of 5.2 per 100,000 with male/female ratio of 0.5:1 among the population. According to the findings by Chibanda, Sebit, and Acuda (2002) in Harare Zimbabwe, the suicide prevalence among the population was discovered to be as high as 49.9 per 100,000 with male/female ratio of 0.2:1.

Suicide has been connected to a number of social circumstances and phenomenon such as unemployment (Jackson \& Warr, 1984), poverty (Skapinakis et al., 2006), economic 
recession (Stack \& Wasserman, 2007), poor governance and degenerating economic situation (Mars et al., 2014), marriage and mental instability (Borum, 2012), gender and gender imbalance (Marion \& Range, 2003), culture and tribal practices (Taylor, 1982), sexuality (Dorais, 2004), religion and ethnicity (Durkheim, 1897), race and racism (Crosby \& Molock, 2006), etc. However, regional differences in the reportage of suicide both in methodology and indices of interest, still leave more to be desired for, in terms of accurate methodology suitable for different regions of the globe with different stages of development.

While the purified indices of suicide and suicide ideation have worked in the developed nations, in encouraging accurate data gathering, religion, suspicion, and dearth of scholarly interest in the phenomenon of suicide have equally made it difficult for the presentation of accurate data on suicide and circumstances surrounding death in the developing nations such as Nigeria (Okafor, 2017). Much of the reported suicide actions and suicide studies in African nations such as Nigeria have been in the newspapers and perhaps the immediate social circumstances of suicide. As such, much is required from the fundamental categorization of suicide and remote social circumstances of suicide as was presented by Durkheim (1897) in the investigation and analysis of suicide potentials in the developing nations such as Nigeria; a task the present study was designed to accomplish.

Many studies have been carried out on suicide action and ideation but with little or no attention to the remote and immediate macro socio-economic factors surrounding suicide tendencies especially, in connection with the four classification of suicide by Durkheim. This is and intellectual exercise, which is much needed in the developing nations such as Nigeria where socio-economic situations and suicide tendencies/actions are still in crude nature and shares fluid relationship with each other.

\section{Theoretical framework}

The theoretical framework of the study anchored on the Durkheimian sociological doctrine of suicide (1897). In the quest for scientific understanding of suicide, Emile Durkheim developed the analytical structure of the immediate and remote causes of suicide taking cognizance of the social structures and available data on regional scale. Durkheim, a functionalist sociologist and one of the founders of the discipline of sociology, was of the view that suicide cannot occur outside the dominant social system, which revolves around the AGIL system (Talccot Parsons, 1951). The AGIL (Adaptation, Goal attainment, Integration and Latency/Pattern maintenance), is in itself, domicile within the four basic structures and functional prerequisite of the society as a whole such as the family, economy, religion, and politics (Durkheim, 1938; Parsons, 1951; Merton, 1968).

Although Durkheim's analysis of suicide was largely on data collected from across Europe during his time, his theoretical grasps on the sociological analysis of the society equally helped him to put the data into proper perspective hence the classification of the types and occurrences of suicide into the socioeconomic designation. Fundamental in Durkheimian sociological suicide doctrine is the fact that suicide is the product of the interaction between the individual/group, and the dominant socioeconomic situation.

Following Durkheim's observation of data on suicide across Europe during his time, suicide was classified into four major types (egoistic, altruistic, fatalistic and anomic suicides) following two major situational circumstances (regulation and integration) (Durkheim, 1897; Haralambose \& Holborn, 2008). Egoistic suicide in Durkheimian classification falls within the situational circumstance of integration. This according to him is caused by insufficient integration by an individual in the social system. This may be as a result of insufficient integration at the family level or the general society by an individual. Altruistic suicide, on the other extreme according to 
Durkheim, is a type of suicide, occurring as a result of excessive integration of the individual into the social system. In this type of suicide, individuals or even a group can take their own lives in the interest of the system they belong to, due to too much attachment to the system. According to Durkheim's classification, anomic suicide occurs as a result of insufficient regulation of the individual activities in the social system. Here, the individuals can fall prey to suicide action induced by uncontrolled excesses ostensibly to exercise freedom.

On the extreme pole of the anomic suicide, is the fatalistic suicide domicile with excessive regulation of the behaviors of the members of the society. In this type of suicide according to Durkheim's classification, excessive regulation in the society including other subgroups individuals can belong to in the social system can result in fatalistic suicide due to knowingly and unknowingly blocking the expectations of some members of the society.

Durkheim's publication on suicide in 1897 latter draw the attention of many researchers, who put forward either a supporting thesis on suicide with regard to Durkheimian perspective or, criticism of Durkheim's perspective (Haralambose \& Holborn, 2008). From what seems to be contrary opinion on Durkheim's explanation of suicide, there are different approaches and perspectives observable.

Douglas (1967) was of the view that Durkheim's analysis using official statistics was wrong considering the understanding that, suicide phenomenon goes beyond official record into individual uniqueness and peculiar situations. Furthermore, Douglas was more interested in the social meaning of suicide order than the causes of the phenomenon such that, he could not agree with Durkheim on the ground that, what was classified as suicide on the statistical ground in reality may not be such if subjected to the dominant understanding and social discuss among a given group. Similarly, Baechler (1979) using a case study, classified suicide into escapist, aggressive, oblative and ludic suicides. According to him, these types of suicide contrary to the earlier classification by Durkheim presented the picture of the circumstances of suicide directly connected to individuals at different circumstances and situations.

Durkheim's sociological doctrine of suicide received more criticisms on the ground that it was derived more from the quantitative approach to sociological studies order than the interpretive approach among some sociologist interested in suicide such as Atkinson (1978), Philipson (1972), Taylor (1982), Dorais (2004), etc. However, the legacy of Durkheim's work endures to date considering, his approach and the goal of mainstream sociology in evaluating and understanding the social phenomena.

While the interpretive sociologists, mostly from the phenomenology quarters were interested in the individually peculiar phenomenon in explaining suicide, they lost the focus of the components of the social system, which are sui generis to the individual members of the society. Sociology as a discipline is more interested in the macrocosm of the social system compared, to the microcosm of the social system. By this understanding, the explanation and analysis of the social phenomenon for a sociologist first, begin by the observation of the social system and structure, and how these affect other issues within the system. Suicide as a social phenomenon is subject to the overwhelming circumstances surrounding the individual members of the society.

Outside Durkheim's use of statistical data in explaining and putting suicide into perspective, his explanation was more of the regulation and integration issues domicile with social structural set up involving the family, religion, politics, and economy. All these put together, appeared as macrocosm interacting with other microelements in the social system, which now have a direct effect on the individual members of the society. As such, what the interpretive sociologists were dabbling with became the further interpretation of the Durkheimian doctrine of suicide. 
For the present study, Durkheim's sociological doctrine of suicide is suitable for understanding and predicting the suicide potential of a sociological group such as students of higher institutions of learning. While egoistic suicide may likely occur among the students due to isolation from the family, students and other related social groups, altruistic suicide can occur among the students due to strong attachment to religious groups, fraternity, students' activism, etc. On the other hand, while fatalistic suicide may likely occur among the students due to excessive regulation from the family, school authority, individual academic staff, etc., anomic suicide may likely occur due to weak regulation from the family, religious group, school authority, etc. All these, are embedded in the four cardinal points of the social structural setup such as the family, religion, politics, and economy. Before now, to the knowledge of the present study, there has not been a study dedicated to the understanding of suicide tendencies in relationship with the macro socio-economic factors especially, in line with Durkheim's classification of suicide.

\section{Methodology}

The study was carried out among three major strands of higher institutions of learning in Nigeria such as universities, polytechnics and colleges of education/agriculture randomly selected from the southeast geopolitical zone of Nigeria comprising, Abia, Anambra, Imo, Enugu and Ebonyi states.

Undergraduate males and females from 17 years and above were selected from ten randomly selected institutions (four universities [2 federal/2state], two polytechnics [federal/state] and four monotechnic (colleges of education, health and agriculture) [federal/state]) using inclusive criteria such as institutions that are in full session within the period (month) of the study.

In each of the institutions, 220 respondents were selected using modified random sampling techniques. The age category in the study was chosen to specifically follow the minimum age requirement for admission into the higher institutions of learning in Nigeria by the National University Commission (NUC) and the Universal Tertiary Matriculation Examination (UTME). The study adopted a cross-sectional survey design. The choice of this design followed the theoretical proposition about the remote and immediate factors to suicide potentials.

While suicide is an action capable of bringing unnatural death, suicide potentials as was couched in this study, is the possibility of suicide thought, if certain socioeconomic circumstances/pressures prevail. The instrument for the study was a survey questionnaire developed on a nominal scale built on the composite of the socioeconomic indices supposedly connected with the four strands of suicides as observed by Durkheim, such as egoistic suicide, altruistic suicide, fatalistic suicide, and anomic suicide.

The socioeconomic indices were captured in the questionnaire and scored with excel data interface as an aid of scoring manual, to isolate the scores for regression analysis. The questionnaires were self-administered with some guidance from the research assistants where the respondents requested for assistance. The data collected were coded and analyzed using Social Science Statistical Package (SPSS version 23) while, the research questions guiding the study were answered with descriptive and inferential statistics such as percentages and Logistic Regression. 
S. O. Okafor - Suicide among Undergraduate Students in Southeast Nigeria: An Empirical...

5. Analysis of the findings

Table 1. Logistic regression on egoistic suicide tendency and other variables

\begin{tabular}{|c|c|c|c|c|c|c|c|c|c|}
\hline & & \multirow[b]{2}{*}{ B } & \multirow[b]{2}{*}{ S.E. } & \multirow[b]{2}{*}{ Wald } & \multirow[b]{2}{*}{ Df } & \multirow[b]{2}{*}{ Sig. } & \multirow[b]{2}{*}{$\operatorname{Exp}(B)$} & \multicolumn{2}{|c|}{$95 \%$ C.Iffor EXP(B) } \\
\hline & & & & & & & & Lower & Upper \\
\hline \multirow[t]{10}{*}{ Step $1^{a}$} & GENDER & -1.971 & .265 & 55.171 & 1 & .000 & .139 & .083 & .234 \\
\hline & Age & -.321 & .176 & $3 \cdot 314$ & 1 & .069 & .725 & .513 & 1.025 \\
\hline & Years spent in school & -.049 & .107 & .208 & 1 & .648 & .952 & $.77^{2}$ & 1.175 \\
\hline & Religion & -1.101 & .145 & $57 \cdot 535$ & 1 & .000 & .333 & .250 & .442 \\
\hline & Income & .301 & .105 & 8.1 .58 & 1 & .004 & 1.351 & 1.099 & 1.661 \\
\hline & Sponsorship & 1.179 & .256 & 21.236 & 1 & .000 & 3.252 & 1.969 & $5 \cdot 370$ \\
\hline & Social activity & .311 & .262 & 1.409 & 1 & .235 & 1.364 & .817 & 2.279 \\
\hline & Religious activities & -.296 & .258 & 1.309 & 1 & .253 & .744 & .448 & 1.235 \\
\hline & Family activities & -.572 & .300 & 3.648 & 1 & .056 & .564 & .314 & 1.015 \\
\hline & Constant & $3 \cdot 362$ & .855 & 15.468 & 1 & .000 & 28.857 & & \\
\hline
\end{tabular}

Dependent Variable: Egoistic Suicide tendency [measured in nominal scale with likely decision response to 5 common socioeconomic stress]

Field Survey, 2019

Overall Percentage classified $=54.6 \%$; Goodness of fit test $=.210 ; \chi^{2}$ Value $=74.824(\mathrm{df} 8) ;$ Cox \& Snell $\mathrm{R}^{2}=$ $34.5 \%$; Nagelkerke $\mathrm{R}^{2}=46.1 \%$

Note: Result is significant at .05 $(p<.05)$

The above Table 1 presented the binary logistic regression on Egoistic Suicide tendency (measured in nominal scale with likely decision response to 5 common socioeconomic stresses) among the students of the higher institutions of learning in southeast Nigeria. The collected data were coded to follow the binary logistic regression default, while the data were test-ran to avoid outliers. The overall strength of the model in explaining the factors surrounding Egoistic Suicide tendency according to the pseudo $\mathrm{R}^{2}$ (Cox \& Snell $\mathrm{R}^{2}$ and Nagelkerke $\mathrm{R}^{2}$ ) is between $34.5 \%$ and $46.1 \%$.

Among the variables of interest, the gender of the students, religion, family income, and sponsorship significantly contributed to the explanation of Egoistic Suicide tendency among the students. Specifically in the model, gender of the students and religion, were in the negative direction according to their B. value, indicating the fact that the more the aforementioned factors, the less the egoistic suicide tendency.

Table 2. Logistic regression on altruistic suicide tendency and other variables

\begin{tabular}{|c|c|c|c|c|c|c|c|c|c|}
\hline & & \multirow[b]{2}{*}{ B } & \multirow[b]{2}{*}{ S.E. } & \multirow[b]{2}{*}{ Wald } & \multirow[b]{2}{*}{ df } & \multirow[b]{2}{*}{ Sig. } & \multirow[b]{2}{*}{$\operatorname{Exp}(B)$} & \multicolumn{2}{|c|}{$95 \%$ Cidufor EXP(B) } \\
\hline & & & & & & & & Lower & Upper \\
\hline \multirow[t]{10}{*}{ Step $1^{a}$} & GENDER & -.201 & .268 & .560 & 1 & .454 & .818 & .484 & $1.3^{84}$ \\
\hline & Age & .041 & .186 & .049 & 1 & .825 & 1.042 & .724 & 1.499 \\
\hline & Years spent in school & .017 & .113 & .022 & 1 & .883 & 1.017 & .815 & 1.269 \\
\hline & Religion & -.522 & .183 & 8.153 & 1 & .004 & .593 & .415 & .849 \\
\hline & Income & .555 & .115 & 23.437 & 1 & .000 & 1.741 & 1.391 & 2.180 \\
\hline & Sponsorship & -.817 & .274 & 8.872 & 1 & .003 & .442 & .258 & .756 \\
\hline & Social activity & -1.191 & .280 & 18.091 & 1 & .000 & .304 & .176 & .526 \\
\hline & Religious activities & -.921 & .299 & $9 \cdot 485$ & 1 & .002 & .398 & .221 & .715 \\
\hline & Family activities & .932 & .325 & 8.198 & 1 & .004 & 2.539 & 1.342 & 4.805 \\
\hline & Constant & 1.179 & .930 & 1.608 & 1 & .205 & 3.250 & & \\
\hline
\end{tabular}

Altruistic Suicide tendency [measured in nominal scale with likely decision response to 5 common socioeconomic stress]

Field Survey, 2019

Overall Percentage classified $=80.0 \% ;$ Goodness of fit test $=.134 ; \chi^{2}$ Value $=56.788(\mathrm{df} 8) ;$ Cox \& Snell R ${ }^{2}=10.8 \% ;$ Nagelkerke R $^{2}=17.1 \%$

Note: Result is significant at .05 $(p<.05)$

The above Table 2 presented the binary logistic regression on Altruistic Suicide tendency (measured in nominal scale with likely decision response to 5 common socioeconomic stresses) among the students of the higher institutions of learning in southeast Nigeria. The collected data were coded to follow the binary logistic regression default, while the data were testran to avoid outliers. The overall strength of the model in explaining the factors surrounding Egoistic Suicide tendency according to the pseudo $\mathrm{R}^{2}$ (Cox \& Snell $\mathrm{R}^{2}$ and Nagelkerke $\mathrm{R}^{2}$ ) is between $10.8 \%$ and $17.1 \%$. 
Among the variables of interest, religion, family income, sponsorship, social activities in school, religious activities in school and family activities significantly contributed to the explanation of Altruistic Suicide tendency among the students. Specifically, in the model, the religion of the students, sponsorship, participation in social activities in school and participation in religious activities in school, were in the negative direction according to their $\mathrm{B}$. value, indicating the fact that the more the aforementioned factors, the less the Altruistic suicide tendency.

Table 3. Logistic regression on anomic suicide tendency and other variables

\begin{tabular}{|c|c|c|c|c|c|c|c|c|c|}
\hline & & \multirow[b]{2}{*}{ B } & \multirow[b]{2}{*}{ S.E. } & \multirow[b]{2}{*}{ Wald } & \multirow[b]{2}{*}{ df } & \multirow[b]{2}{*}{ Sig. } & \multirow[b]{2}{*}{$\operatorname{Exp}(\mathrm{B})$} & \multicolumn{2}{|c|}{$9.5 \%$ C.Ifor EXP(B) } \\
\hline & & & & & & & & Lower & Upper \\
\hline \multirow[t]{10}{*}{ Step $1^{a}$} & GENDER & -1.348 & .228 & 3.5 .108 & 1 & .000 & .260 & .166 & .406 \\
\hline & Age & -.640 & .170 & 14.179 & 1 & .000 & .527 & .378 & .736 \\
\hline & Years spent in school & .217 & .097 & 5.000 & 1 & .025 & 1.242 & 1.027 & 1.502 \\
\hline & Religion & -.235 & .124 & 3.592 & 1 & .058 & .791 & .620 & 1.008 \\
\hline & Income & .135 & .091 & 2.201 & 1 & .138 & 1.144 & $.95^{8}$ & 1.368 \\
\hline & Sponsorship & -.275 & .241 & $1.3 \circ 3$ & 1 & .254 & .760 & .474 & 1.218 \\
\hline & Social activity & -.536 & .226 & 5.613 & 1 & .018 & .585 & .376 & .912 \\
\hline & Religious activities & -.818 & $.23^{8}$ & 11.760 & 1 & .001 & .441 & .277 & .704 \\
\hline & Family activities & -.9 .31 & .270 & 11.904 & 1 & .001 & .394 & $.2,32$ & .669 \\
\hline & Constant & 6.160 & .892 & 47.717 & 1 & .000 & 473.440 & & \\
\hline
\end{tabular}

Anomic Suicide tendency [measured in nominal scale with likely decision response to 5 common socioeconomic stress]

Overall Percentage classified $=67.0 \%$; Goodness of fit test $=.213 ; \chi^{2 \text { Value }}=31.611$ (df8); Cox \& Snell R ${ }^{2}=24 \cdot 3 \% ;$ Nagelkerke $\mathrm{R}^{2}=32.5 \%$ Note: Result is significant at .05 $(p<.05)$

The above Table 3 presented the binary logistic regression on Anomic Suicide tendency (measured in nominal scale with likely decision response to 5 common socioeconomic stresses) among the students of the higher institutions of learning in southeast Nigeria. The collected data were coded to follow the binary logistic regression default, while the data were testran to avoid outliers. The overall strength of the model in explaining the factors surrounding Egoistic Suicide tendency according to the pseudo $\mathrm{R}^{2}$ (Cox \& Snell $\mathrm{R}^{2}$ and Nagelkerke $\mathrm{R}^{2}$ ) is between $24.3 \%$ and $32.5 \%$.

Among the variables of interest, gender, age, number of years in school, social activities in school, religious activities in school and family activities significantly contributed to the explanation of Anomic Suicide tendency among the students. Specifically in the model, gender, religion of the students, participation in social activities in school, participation in religious activities in school and family activities were in the negative direction according to their $\mathrm{B}$. value, indicating the fact that the more the aforementioned factors, the less the Anomic suicide tendency.

Table 4. Logistic regression on fatalistic suicide tendency and other variables

\begin{tabular}{|c|c|c|c|c|c|c|c|c|c|}
\hline & & \multirow[b]{2}{*}{ B } & \multirow[b]{2}{*}{ S.E. } & \multirow[b]{2}{*}{ Wald } & \multirow[b]{2}{*}{ df } & \multirow[b]{2}{*}{ Sig. } & \multirow[b]{2}{*}{$\operatorname{Exp}(B)$} & \multicolumn{2}{|c|}{$95^{\%} \%$ C.I.for EXP(B) } \\
\hline & & & & & & & & Lower & Upper \\
\hline \multirow[t]{10}{*}{ Step $1^{a}$} & GENDER & -1.711 & .278 & 37.817 & 1 & .000 & .181 & .105 & .312 \\
\hline & Age & -.474 & .196 & 5.860 & 1 & .015 & .623 & .424 & .914 \\
\hline & Years spent in school & -.124 & .116 & $1.13^{2}$ & 1 & .287 & .883 & .703 & 1.110 \\
\hline & Religion & -1.604 & .184 & 76.152 & 1 & .000 & .201 & .140 & .288 \\
\hline & Income & .382 & .109 & 12.363 & 1 & .000 & 1.465 & 1.184 & 1.812 \\
\hline & Sponsorship & -.375 & .275 & 1.853 & 1 & .173 & .687 & .401 & 1.179 \\
\hline & Social activity & -1.081 & .264 & 16.703 & 1 & .000 & .339 & .202 & .570 \\
\hline & Religious activities & -.222 & .277 & .642 & 1 & .423 & .801 & .466 & 1.378 \\
\hline & Family activities & .528 & .316 & 2.798 & 1 & .094 & 1.69 .5 & .913 & 3.146 \\
\hline & Constant & 7.737 & 1.020 & $57 \cdot 582$ & 1 & .000 & 2291.996 & & \\
\hline
\end{tabular}

Fatalistic Suicide tendency [measured in nominal scale with likely decision response to 5 common socioeconomic stress]

Overall Percentage classified $=82.0 \%$; Goodness of fit test $=.215 ; \chi^{2}$ Value $=125.33^{8}$ (df8); Cox \& Snell R ${ }^{2}=38.4 \% ;$ Nagelkerkel $\mathrm{R}^{2}=51.8 \%$ Note: Result is significant at .05 $(p<.05)$.

The above Table 4 presented the binary logistic regression on fatalistic Suicide tendency (measured in nominal scale with likely decision response to 5 common socioeconomic 
stresses) among the students of the higher institutions of learning in southeast Nigeria. The collected data were coded to follow the binary logistic regression default, while the data were testran to avoid outliers. The overall strength of the model in explaining the factors surrounding fatalistic Suicide tendency according to the pseudo $\mathrm{R}^{2}$ (Cox \& Snell $\mathrm{R}^{2}$ and Nagelkerke $\mathrm{R}^{2}$ ) is between $38.4 \%$ and $51.8 \%$.

Among the variables of interest, age, the gender of the students, religion, family income and participation in social activities in school significantly contributed to the explanation of fatalistic Suicide tendency among the students. Specifically in the model, gender of the students, age, sponsorship, participation in social activities in school and religion, were in the negative direction according to their B. value, indicating the fact that the more the aforementioned factors, the less the egoistic suicide tendency.

Figure 1. Display of suicide tendencies

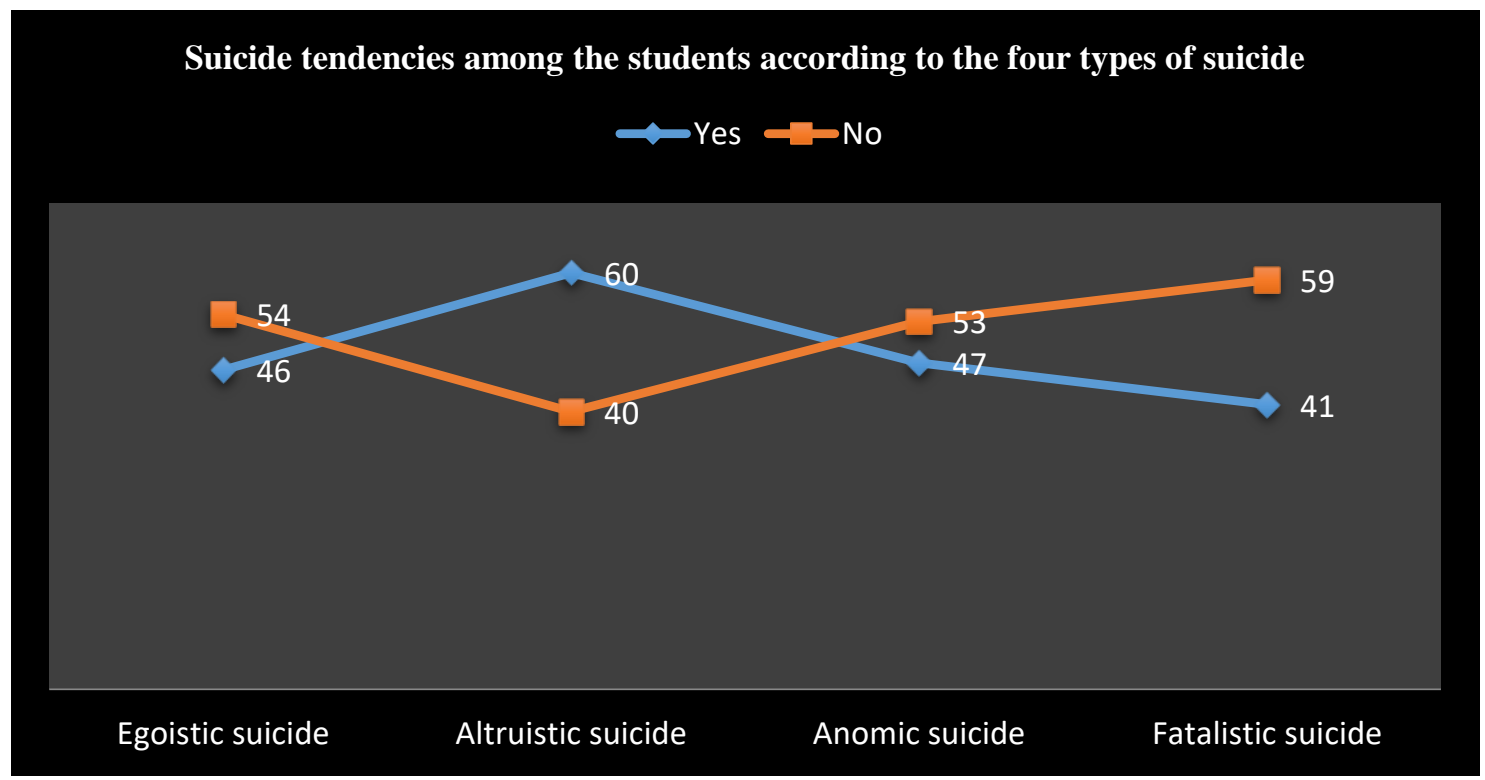

Source: Field Survey, 2019

The above chart in Figure 1 presented the presence of the likelihood of suicide tendency among the students by types of suicide. As they appeared in the chart above, there are the presence of the different types suicides as classified by the Durkheimian suicide thesis. While fatalistic suicide tendency was the lowest among the study participants (41\%), egoistic suicide tendency is $46 \%$ while anomic suicide tendency is at $47 \%$. The top most suicide tendency among the forms of suicides is altruistic suicide tendency $(60 \%)$.

\section{Discussion of the findings}

The focus of the study was to ascertain the presence and extent of suicide tendency among undergraduate students in the southeast region of Nigeria. Keeping in view, the multifaceted nature of suicide and suicide tendency, the study narrowed down to Durkheimian suicide doctrine as a point of departure from the regular approach to the study suicide tendency/ideation (Gureje et al., 2007; Gunnell et al., 2012; Saurina et al., 2013; Chang, Stuckler, Yip \& Gunnell, 2013), while reaffirming the indispensability of the macro socio-economic factors in the understanding of the remote and immediate factors to suicide tendency (Goodman, 1999; Chandler, 2019; Durkheim, 2006[1897]). More so, the study was designed to bring into account, 
the crude nature of suicide tendencies, and the fluid boundary between the remote factors and immediate factors of suicide action among the youth in the developing nations such as Nigeria.

From the finding of the study, there are indices of suicide tendency of the four types of suicide according to the Durkheimian suicide analysis. Although suicide actions among the developing nations are much considered on the line of completed suicide (WHO, 2018), the uncompleted suicide appears to be ignored. And this is mostly connected to the remote socioeconomic factors. Similar findings by other researchers such as Furr, Westefeld, McConnell, and Jenkins (2001), and Westefeld et al. (2005) revealed that suicide tendencies among the youth can be larger than we can assume, and functions as remote factor to trigger off suicide. As pertain to this study, the findings unveiled the unseen remote factor, which has triggered the recent issues of suicides recorded in a number of higher institution in the southeast Nigeria and other parts of the nation bringing to the limelight of the global research community, the relevance of Durkheim's classification of suicide and socio-economic factors.

Fatalistic suicide tendency was found to be the lowest among the study participants (41\%). However, this type of suicide tendency was only positively correlated with the family income but was negatively correlated with other factors such as age, gender, participation in social and religious activities in the school, sponsorship. By implication, the finding indicated the role of family income to the extreme level of socioeconomic aspiration among the students. The findings here supported the study by Borowsky, Resnick, Ireland and Blum (1999), which revealed the positive functions of macro socio-economic factors in reducing suicide tendency among the college students. Equally, the finding here revealed the importance of Durkheim's classification of suicide in tracking the hidden nature of different types of suicide especially the fatalistic suicide, which ostensibly operate as displaced aggression among the college students in the developing nations.

Egoistic suicide tendency was found to be $46 \%$ among the students under study. In Durkheimian suicide analysis, this type of suicide has more to do with isolation and personal evaluation compared to other forms of suicide. Egoistic suicide tendencies appearing with $46 \%$ among these students revealed the heterogeneous appearance of social and religious activities among these students in the region. This type of suicide tendency was only positively related to family income and the source of sponsorship among the students under study. Although there is extraneous variable(s) that exist between egoistic suicide tendency and the aforementioned two variables, the findings in its current appearance indicate the influence of higher family income instead of poverty, on the problem of egoistic suicide. Family affluence, more than creating satisfaction, can cause unseen isolation and by extension, suicide imagery (Haw \& Hawton, 2011). However, the negative $\mathrm{B}$ values of the gender of the students and religion point to the unseen role of religion and gender in balancing the issue of egoistic suicide.

The study by Borowsky et al. (1999) equally proved the fact that gender is a factor to suicide attempts among the college students. On the issue of religion and egoistic suicide, from the preliminary analysis, Christians were more in the study compared to other religious affiliations. At the surface, we take this to be a result of a loosed relationship between the majority of these students and their religious activities as well as weak internal cohesion among the student worshipers. However, the positive role of religiosity and egoistic suicide tendency can be proving via the logistic regression on the variables. The finding corroborated the findings of the study by Marion and Range (2003) that, religiosity appears as a proof against suicide. While their findings was under the design of suicide phenomenon in a composite nature, the present study contributes to the ongoing researches on suicide, by isolating different types of suicides especially the egoistic suicide tendency and the remote macro socio-economic factors surrounding it.

Anomic suicide tendency is at $47 \%$. Anomic suicide specifically is connected with weak regulation as well as high social current (Durkheim, 2006[1897]). Among the students, the presence of anomic suicide speaks volumes about the weak social bonds in the family and other 
social institutions connected to the undergraduate students such as the institutional setup on the regulation of students' individual and collective activities. Regulation here per se is not on the extant rules of the higher institutions of learning backed up with some level of punishments but some emotional regulation in terms of students' orientation from time to time by the institutional authority with a focus on controlling inordinate ambitions among the students. As a matter of fact, the variable is only positively correlated in the model with how many years the students have been in the school but negatively correlated with other socio-demographic variables such as gender, the religion of the students, participation in social activities in school, participation in religious activities in school and family activities.

The studies by Borowsky et al. (1999) and Marion and Range (2003) complement this finding. According to their findings, religiosity, family ties, social activities, etc., function as protective factors against suicide. While their findings appeared on the studies that approached suicide as a composite factor, the present study's finding has a point of departure as further isolation of suicide into types and tendencies bringing to the limelight of the researching community, the forms of suicide according to the Durkheim's classification and their accompanying social current.

The topmost suicide tendency among the forms of suicides is altruistic suicide tendencies (60\%). Altruistic suicide, the opposite of egoistic suicide according to Durkheim's suicide analysis, is a form of suicide in which collective conscience (Durkheim's term for a cooperative living) affects the individual willingness to take the risk or even lay their lives for the interest of the group in question. In the model, two variables were positively correlated with altruistic suicide tendencies such as family income and participation in family activities. At the surface, the correlation of altruistic suicide tendency, family income and participation in family activities reveals the effect of the dominant culture of pressure on the youth in southeast Nigeria from the family. In the other direction, altruistic suicide tendency is negatively correlated with other variables such as the religion of the students, sponsorship, participation in social activities in school and participation in religious activities in school.

This further shows that family ties are more superior on the scale of preference of the students compared to other social attachments. Although O’Donnell et al. (2004) and Borowsky et al. (1999) reported family ties as a protective factor against egoistic suicide; the findings here appeared otherwise and as such, unveiled the fluid relationship between suicide tendencies and socio-economic pressure originating from the family. And, as part of the goal of this study, it has made known to the global research community, the unseen contribution of family socio-economic pressure to the existence of altruistic suicide.

\section{Conclusion}

Suicide as a social phenomenon is embedded in the prevailing socio-economic circumstances (social current) of the time and by implication vulnerable to the negative or positive direction, and influence of the indices of the socio-economic situation of the time. Among other areas of interest, the undergraduate students in southeast Nigeria and the current socio-economic situation in Nigeria rightly fall in place in the question of ongoing empirical investigation of suicide phenomenon world over. However, for clarity purposes, the present study focused on the Durkheimian sociological suicide analysis as a point of departure from the dominant trend on suicide studies before now. Following the formulation and instrument designed for this study, the findings of the study pointed to the rising suicide tendency among these undergraduate students. While the study was more of investigating the remote factors surrounding the likelihood of suicide thought among the students under study, the instrument for the study was designed to capture some dominant socio-economic factors at the students' level, capable of testing their likely response to extreme conditions of life in different directions. While in the overall findings, 
altruistic suicide tendency is high (60\%), this is followed by anomic suicide tendency (47\%), egoistic suicide tendency (46\%) and fatalistic suicide tendency (41\%). From the regression model, the altruistic suicide tendency was found to be positively correlated with family income and strong ties with family activities. Equally, the anomic suicide tendency was found to be positively correlated with how many years the students have been in the school. Egoistic suicide tendency was found to be positively correlated with family income and source of sponsorship while fatalistic suicide tendency was found to be positively correlated with only family income. The study findings contribute to the ongoing discussions on suicide, the indispensability of the remote macro socioeconomic factors among the developing nation, in understanding the phenomenon of suicides especially with regard to Durkheim's classification of suicide.

\section{Acknowledgements}

This research did not receive any specific grant from funding agencies in the public commercial, or not-for-profit sectors.

The author declares no competing interests.

\section{References}

Adewuya, A. O., Ola, B. A., Olurotimi, A. C., Olayinka, A., Mathew, P. Z., Olufemi, O., Adedolapo, F., \& Olajide, I. (2016). Prevalence and associated factors for suicidal ideation in the Lagos State Mental Health Survey, Nigeria. BJ Psych Open, 2, 385-389. https://doi.org/10.1192/bjpo.bp.116.004333

Adinkrah, M. (2011). Epidemiologic characteristics of suicidal behavior in contemporary Ghana. Crisis, 32(1), 31-36.

Agoub, M., Moussaoui, D., \& Kadri, N. (2006). Assessment of suicidality in a Moroccan metropolitan area. $J$ Affect Disord, 9o(2), 223-226.

Atkinson, J. (1978). Societal reactions to suicide. In Discovering suicide. London: Macmillan.

Atkinson, J. M. (1978). Discovering suicide. Studies in the social organization of sudden death. Pittsburgh, PA: University of Pittsburgh Press.

Baechler, J. (1979). Suicides. Oxford: Blackwell.

Bekry A. A. (1999). Trends in suicide, parasuicide and accidental poisoning in Addis Ababa, Ethiopia. Ethiop J Health Dev, 13(3), 247-262.

Borowsky, 1. W., Resnick, M. D., Ireland, M., \& Blum, R. W. (1999). Suicide attempts about American Indian and Alaska Native youth. Archives of Pediatric \& Adolescent MediCine, 153, 573-580.

Borowsky, 1. W., Resnick, M. D., Ireland, M., \& Blum, R. W. (1999). Suicide attempts about American Indian and Alaska Native youth. Archives of Pediatric \& Adolescent MediCine, 153, 573-580.

Borum, V. (2012). African American women's perceptions of depression and suicide risk and protection: A womanist exploration. Affilia, 27(3), 316-327.

Boyce, C. J., Delaneya, L., Ferguson, E., \& Wood, A. M. (2018). Central bank interest rate decisions, Household indebtedness, and psychiatric morbidity and distress: Evidence from the UK. Journal of Affective Disorders, 234, 311-317. 
S. O. Okafor - Suicide among Undergraduate Students in Southeast Nigeria: An Empirical...

Boyce, C. J., Wood, A. M., \& Ferguson, E. (2016). Individual differences in loss aversion: conscientiousness predicts how life satisfaction responds to losses versus gains in income. Personal. Soc. Psychol. Bull., 42, 471-484.

Chandler, A. (2019). Socioeconomic inequalities of suicide: Sociological and psychological intersections. Eur. J. Soc. Theory, 2019, 1-19.

Chang, S.-S., Stuckler, D., Yip, P., \& Gunnell, D. (2013). Impact of 2008 global economic crisis on suicide: time trend study of 54 countries. BMJ Open Access. 347, f5239. http://dx.doi.org/10.1136/bmj.f5239

Chibanda, D., Sebit, M., \& Acuda, S. (2002). Prevalence of major depression in deliberate self-harm individuals in Harare, Zimbabwe. East Afr Med J, 79(5), 263-266.

Coope, C., Gunnell, D., Hollingworth, W., Hawton, K., Kapur, N., Fearn, V., \& Metcalfe, C. (2014). Suicide and the 2008 economic recession: Who is most a trisk? Trends in suicide rates in England and Wales 2001-2011. Social Science and Medicine, 117, 76-85.

Crosby, A., \& Sherry, D. M. (2006). Suicidal behaviors in the African American community. The Journal of BlackPsychology, 32(3), 1-9.

Dorais, M. (2004). Dead boys can't dance: Sexual orientation, masculinity and suicide. Montreal: MacGillQueen's University Press.

Douglas, J. D. (1967). The social meaning of suicide. New Jersey: Princeton University Press.

Durkheim, E. (1897). Le suicide: étude de sociologie.

Durkheim, E. (1938). The rules of sociological method. New York: Free Press.

Durkheim, E. (2006 [1897]). On suicide. London, England: Penguin Classics.

Dzamalala, C. P., Milner, D. A., \& Liomba, N. G. (2006). Suicide in Blantyre, Malawi (2000-2003). J Clin ForensicMed, 13(2), 65-69.

Facts and figures [Fact sheet] (2010). Retrieved 16 December 2019, from American Foundation for Suicide Prevention website.

Fitzpatrick, S. (2018). Reshaping the ethics of suicide prevention: Responsibility, inequality, and action on the social determinants of suicide. Public Health Ethics, 11, 179-190.

Furr, S. R., Westefeld, J. S., McConnell, G. N., \& Jenkins, J. M. (2001). Suicide and depression among college students: A decade later. Professional Psychology: Research and Practice, 32, 91-100.

Goodman, E. (1999). The role of socioeconomic status gradients in explaining differences in US adolescents' health. American Journal of Public Health, 89, 1522-1528.

Gunnell, D., Bennewith, O., Simkin, S., Cooper, J., Klineberg, E., Rodway, C., \& Kapur, N. (2012). Time trends in coroners' use of different verdicts for possible suicides and their impact on officially reported incidence of suicide in England: 1990-2005. Psychol. Med., 1-8. http://dx.doi.org/10.1017/So033291712002401

Gureje, O., Kola, L., Uwakwe, R., Udofia, O., Wakil, A., \& Afolabi, E. (2007). The profile and risks of suicidal behaviours in the Nigerian Survey of Mental Health and Well-Being. Psychol Med, $37(6), 821-830$.

Haw, C., \& Hawton, K. (2011). Living alone and deliberate self-harm: A case-control study of characteristics and risk factors. Soc Psychiatry Psychiatr Epidemiol, 46, 1115-1125.

Hawton, K., \& van Heeringen, K. (2009). Suicide. Lancet, 373, 1372-1381.

Hawton, K., Saunders, K. E., \& O’Connor, R. C. (2012). Self-harm and suicide in adolescents. Lancet, 379, 2373-2382.

Henry, A. F., \& Short, J. F. (1954). Homicide and suicide. London: Macmillan.

Hindess, B. (1973). The use of official statistics in sociology: A critique of positivism. London: Macmillan. 
Hjelmeland, H., \& Knizek, B. L. (2010). Why we need qualitative research in suicidology. Suicide Life Threat. Behav., (40), 74-80.

Holmes, E. A., Crane, C. Fennell, M. J. V., \& Williams, J. M. G. (2007). Imagery about suicide in depression-"Flash-forwards"? J Behav Ther Exp Psychiatry, 38(4), 423-434.

Holt, M. K., Vivolo-Kantor, A. M., Polanin, J. R., Holland, K. M., DeGue, S., Matjasko, J. L., Wolfe, M., \& Reid, G. (2015). Bullying and suicidal ideation and behaviors: A meta-analysis. PEDIATRICS, 135(2), 496-509. http://dx.doi.org/10.1542/peds.2014-1864

Ikealumba, N. V., \& Couper I. D. (2006). Suicide and attempted suicide: The Rehoboth experience. Rural Remote Health, 6(535), 1.

Jackson, P. R., \& Warr, P. B. (1984). Unemployment and psychological ill-health: The moderating role of duration and age. Psychol. Med., 14(3), 605-614.

http://dx.doi.org/10.1017/So03329170001521X

João, P. S., Tavares, M., \& Barros, P. P. (2016). More than just numbers: Suicide rates and the economic cycle in Portugal (1910-2013). SSM -Population Health, 2 14-23.

Joe, S., Stein, D. J., Seedat, S., Herman, A., \& Williams, D. R. (2008). Non-fatal suicidal behavior among South Africans. Soc Psychiatry Psychiatr Epidemiol, 43(6), 454-461.

Joe, S., Baser, R. S., Neighbors, H. W., Caldwell, C. H., \& Jackson, J. S. (2009). 12-month and lifetime prevalence of suicide attempts among black adolescents in the National Survey of American Life. Journalof the American Academy of Child and Adolescent Psychiatry, 48(3), 271-282.

Johnson, K., Asher, J., Rosborough, S., Raja, A., Panjabi, R., Beadling, C., \& Lawry, L. (2008). Association of combatant status and sexual violence with health and mental health outcomes in post conflict Liberia. JAMA, 30o(6), 676-690.

Kinyanda, E., Hjelmeland, H., \& Musisi, S. (2004). Deliberate self-harm as seen in Kampala, Uganda. Soc Psychiatry Psychiatr Epidemiol, 39(4), 318-325.

Kirmayer, L. J., Brass, G. M., Holton, T., Paul, K., Simpson, C., \& Tait, C. (2007). Suicide among Aboriginal Peoples in Canada. Ottawa: Aboriginal Healing Foundation.

Lester, B. Y. (2001). Learnings from Durkheim and beyond: The economy and suicide. Suicide and LifeThreatening Behavior, 31(1), 15-31.

Marion, M. S., \& Range, L. M. (2003). Do extenuating circumstances influence African American women's attitudes toward suicide? Suicide \& Life-Threatening Behavior, 33(1), 44-51.

Marion, M. S., \& Range, L. M. (2003). African American college women's suicide buffers. The American Association of Suicidology, 33(1), 33-43.

Mars, B., Burrows, S., Hjelmeland, H., \& Gunnell, D. (2014). Suicidal behaviour across the African continent: A review of the literature. BMC Public Health, 14, 606 http://www.biomedcentral.com/1471-2458/14/606.

Merton, R. (1968). Social theory and social structure. New York: Free press.

Mills, C. (2018). Dead people don't claim: A psychopolitical autopsy of UK austerity suicides. Crit. Soc. Policy, 38, 302-322.

Ndosi, N. K., Waziri, M. C. (1997). The nature of parasuicide in Dar es Salaam, Tanzania. Soc Sci Med, 44(1), $55-61$.

Nock, M. K., Borges G., \& Ono, Y. (Eds). (2012). Suicide: Global perspectives from the WHO World Mental Health Surveys. Cambridge: Cambridge University Press.

Nock, M. K., Borges, G., \& Bromet, E. J. (2008). Cross-national prevalence and risk factors for suicidal ideation, plans and attempts. Br J Psychiatry, 192, 98-105.

O'Connor, R. C., \& Nock, M. K. (2014). The psychology of suicidal behaviour. Lancet Psychiatry, 1, 73-85. http://dx.doi.org/10.1016/S2215-0366(14)70222-6 
O’Donnell, L., O’Donnell, C., Wardlaw, D. M., \& Stueve, A. (2004). Risk and resiliency factors influencing suicidality among urban African American and Latino youth. American Journal of Community Psychology, 33(112), 37-49.

Okafor, S. O. (2017). Culture, perception/belief about death and their implication to the awareness and control of the socio-economic, environmental and health factors surrounding lower life expectancy in Nigeria. Acta Psychopathologica, 3(5), 56. http://dx.doi.org/10.4172/2469$\underline{6676.100128}$

Parsons, T. (1951). The social system. New York: Free press.

Philipson, M. (1972). Theory methodology and conceptualization. In P. Filmer et al. (Eds.), New direction in sociological studies. London: Collier-Macmillan.

Pollock, N., Healy, G., Jong, M., Valcour, J., \& Mullay, S. (2018). Tracking progress in suicide prevention in Indigenous communities: A challenges for public heath surveillance in Canada. BMC Public Health, 18, 13-20.

Reeves, A., Stuckler, D., McKee, M., Gunnell, D., Chang, S.-S., \& Basu, S., (2012). Increase in state suicide rates in the USA during economic recession. Lancet, 38o(9856), 1813-1814.

Saurina, C., Bragulat, B., Saez, M., \& Lopez-Casasnovas, G., (2013). A conditional model for estimating the increase in suicides associated with the 2008-2010 economic recession in England. J. Epidemiol. Comm. Health. http://dx.doi.org/10.1136/jech-2013-202645

Scourfield, J., Fincham, B., Langer, S., \& Shiner, M. (2012). Autopsy: An integrated approach to the study of suicide in men. Social Science \& Medicine, 74, 466-473.

Skapinakis, P., Weich, S., Lewis, G., Singleton, N., \& Araya, R. (2006). Socio-economic position and common mental disorders: longitudinal study in the general population in the UK. Br. $J$. Psychiatry, 189(2), 109-117. http://dx.doi.org/10.1192/bjp.bp.105.014449

Skinner, R., \& McFaull, S. (2012). Suicide among children and adolescents in Canada: Trends and sex differences, 1980-2008. Can. Med Assoc. J., 184, 1015-1016.

Spates, K., \& Slatton, B. C. (2017). I've got my family and my faith: Black women and the suicide paradox. Dynamic World, 3, 1-9. http://dx.doi.org/10.1177/2378023117743908

Stack, S., \& Wasserman, I., (2007). Economic strain and suicide risk: A qualitative analysis. Suicide LifeThreat. Behav., 37(1), 103-112.

Taylor, S. (1982). Durkheim and the study of suicide. London: Macmillan.

Westefeld, J. S., Homaifar, B., Spotts, J., Furr, S., Range, L., \& Werth, J. L. (2005). Perceptions concerning college student suicide: Data from four universities. Suicide and Life-Threatening Behavior, $35(6), 640-645$.

White, J., \& Morris, J. (2019). Re-thinking ethics and politics in suicide prevention: Bringing narrative ideas into dialogue with critical suicide studies. Int. J. Environ. Res. Public Health, 16, 32-36. http://dx.doi.org/10.3390/ijerph16183236

World Bank Group (2017). World Bank development report-governance and law. Washington, DC: International Bank for Reconstruction and Development / The World Bank.

World Health Organization (2018a). Global Health Estimates 2016: Deaths by cause, age, sex, by country and by region, 2000-2016. Geneva: World Health Organization.

World Health Organization (2018b). National suicide prevention strategies: progress, examples and indicators. Geneva: World Health Organization.

World Health Organization (2019). Suicide in the world: Global Health Estimates. Geneva: World Health Organization. 
Open Journal for Anthropological Studies, 2020, 4(2), 35-50.

C O A $\mathrm{s}$ 